\title{
Røykeforbud på serveringssteder og luftveissymptomer blant ansatte
}

\begin{abstract}
Sammendrag
Bakgrunn. Vi har tidligere rapportert forekomsten av luftveissymptomer, kotininkonsentrasjon i urin og lungefunksjon blant ansatte i 13 ulike barer og restauranter før og etter at røykeforbudet ved serveringssteder trådte i kraft i 2004. Den samme studien inneholdt en spørreskjemaundersøkelse om luftveissymptomer hos de ansatte før og etter røykeforbudet. I denne artikkelen rapporterer vi funnene fra spørreskjemaundersøkelsen.
\end{abstract}

Materiale og metode. Studien inkluderte 93 menn og kvinner. Disse ble fulgt i løpet av et skift før røykeforbudet og 3-8 måneder senere. Initialt besvarte 86 av deltakerne et spørreskjema om symptomer fra luftveiene, mens 67 gjorde det ved etterundersøkelsen.

Resultater. Før røykeforbudet rapporterte 39 av $86(45,3 \%)$ at de noensinne hadde hatt piping i brystet, og 28 $(32,6 \%)$ sa at de nylig hadde hatt luftveisinfeksjon. Av de 67 som besvarte spørreskjemaet på begge tidspunktene, anga 43,3\% færre symptomer og 20,9\% flere symptomer etter røykeforbudet, mens $35,8 \%$ rapporterte om samme antall symptomer. Tilsvarende tall blant røykerne var $47,5 \%, 15,0 \%$ og $37,5 \%$.

Fortolkning. Denne studien viser at innføring av røykeforbud på serveringssteder kan være gunstig for helsen til de ansatte. En stor andel rapporterte imidlertid om flere symptomer etter forbudet.

\author{
Marit Skogstad \\ marit.skogstad@stami.no \\ Statens arbeidsmiljøinstitutt \\ Kristina Kjærheim \\ Kreftregisteret
}

Geir Fladseth

Occupational Hygiene Solutions

\section{Pål Molander}

Statens arbeidsmiljøinstitutt

Det har i mange år vært et sterkt søkelys på helsekonsekvenser ved eksponering for passiv røyking. Et generelt røykeforbud på arbeidsplassene ble iverksatt fra 1988, men først i 2004 fikk arbeidstakere på serveringssteder et røykfritt arbeidsmiljø.

Eksponering for passiv røyking er forbundet med mange negative helseeffekter, slik som økt risiko for lungekreft, kronisk obstruktiv lungesykdom (kols) og hjerte- og karsykdommer (1-5). Sidestrømmen i sigaretten inneholder mange irriterende og toksiske forbindelser på linje med det man finner i hovedstrømmen (6). Symptomer som irritasjon av øyne, luftveier og hals pga. passiv røyking på arbeidsplasser kan gi like mye helseplager som det å oppholde seg i private hjem der det røykes $(7,8)$.

I forbindelse med innføring av røykeforbud på serveringssteder 1.6. 2004 ba vi arbeidstakere ved et utvalg barer og restauranter i Oslo rapportere sine aktuelle og tidligere symptomer fra luftveiene ved hjelp av et fokusert spørreskjema. Parallelt med dette undersøkte vi nivået av totalstøv og nikotin i arbeidsatmosfæren, lungefunksjonen ble målt før og etter skiftet og urin-kotininkonsentrasjonen umiddelbart etter skiftet og neste morgen $(9,10)$. Alle undersøkelsene ble gjort både før og etter røykeforbudet. Vi fant en betydelig nivåreduksjon i nikotin og totalstøv i arbeidsatmosfæren, en reduksjon i kotininnivåene blant både røykere og ikkerøykere, samt mindre fall i lungefunksjon i løpet av skiftet etter innføring av røykeforbudet $(9,10)$.

I denne artikkelen vil vi begrense oss til å rapportere funn fra spørreskjemaundersøkelsen om luftveissymptomer før og etter røykeforbud på serveringssteder.

\section{Materiale og metode}

En detaljert beskrivelse av materiale og metode er blitt publisert tidligere $(9,10)$. Til sammen ble 15 barer og restauranter valgt ut til å delta i undersøkelsen. Utvelgelsen skjedde i samarbeid med arbeidsgiver- og arbeidstakerorganisasjonene, slik at de skulle gjenspeile bransjen i Oslo. De ansatte på to av arbeidsplassene ønsket ikke å delta, så ansatte ved 13 restauranter og barer ble studert. Ved disse enhetene ble alle aktuelle personer $(\mathrm{n}=112)$ spurt om å delta, hvorav 93 (47 kvinner og 46 menn) ga sitt samtykke. Gjennomsnittsalderen i gruppen var 30,7 år (spredning 19-55 år), og 52,7 \% var dagligrøykere (9).

Den første undersøkelsen fant sted i løpet av mai 2004, og undersøkelsen etter introduksjon av røykeforbudet ble utført 3-8 måneder senere. På oppfølgingstidspunktet hadde åtte personer sluttet i arbeidet, åtte var på ferie eller hadde permisjon, tre hadde forandret sine røykevaner og fem hadde forlatt arbeidet pga. innskrenkninger på arbeidsplassen, slik at til sammen 69 personer, hvorav 35 kvinner ble undersøkt. I første runde mottok vi totalt 86 besvarte spørreskjemaer, 41 kvinner (gjennomsnittsalder 30 år, SD = 8,2) og 45 menn (31 år, SD = 7,3). Av disse besvarte 67 spørreskjemaet også ved oppfølgingsundersøkelsen, 34 kvinner (30 år, SD = 8,3) og 33 menn (32 år, SD = 7,0).

Studien er godkjent av Datatilsynet, anbefalt av Regional komité for medisinsk etikk Sør og basert på skriftlig informert samtykke fra deltakerne.

De fleste deltakerne arbeidet kveldsskift. De begynte å jobbe på ettermiddagen og gikk fra arbeidet ved midnatt eller noen timer senere. Den samme skiftplanen ble brukt ved oppfølgingsrunden - alle deltakerne jobbet samme tid ved begge anledninger.

For identifikasjon av luftveissymptomer brukte vi et modifisert spørreskjema av British Medical Research Council Questionnaire (11). Dette skjemaet (tab 1) inneholder 13 spørsmål om tilstedeværelse eller ikke av ulike luftveissymptomer, og en kontinuerlig

\section{Hovedbudskap}

- En høyere andel ansatte ved serveringssteder rapporter om færre symptomer fra luftveiene etter at røykeforbudet ble innført enn om flere eller samme antall

- Det var likevel en av fem som rapporterte om flere symptomer etter at røykeforbudet ble innført 
symptomskår ble beregnet ved en enkel summasjon av antall positive svar. I tillegg ble svarene gruppert i fire symptomgrupper: akutt hoste/oppspytt (spørsmål 1-3), persisterende hoste og oppspytt (spørsmål 4-5), grad av dyspné (spørsmål 6-10), opplevelse av piping i brystet (spørsmål 11) og analysert hver for seg. I et tilleggsspørreskjema ble det spurt om astma der «astmadiagnose stilt av lege» ble brukt for å karakterisere forsøkspersoner som astmatikere. De som røykte daglig ved studiens start ble definert som røykere. Tidligere røykere og de som aldri hadde røykt ble definert som ikke-røykere.

\section{Statistikk}

Symptomangivelser før og etter røykeforbudet ble sammenliknet som parede proporsjoner i programmet $\mathrm{R}$ (R,Version 2.1.1. The R Foundation for Statistical Computing, 6-20-2005), der de 67 personene ble inkludert som hadde svart på spørreskjemaet ved begge anledninger.

\section{Resultater}

Tabell 1 viser antall respondenter som oppga de ulike luftveissymptomer før røykeforbudet hos de 86 personene som da svarte på alle spørsmålene på spørreskjemaet. Tabell 2 viser andelen av de 67 i oppfølgingen som anga færre, flere eller samme antall luftveissymptomer etter innføring av røykeforbudet, både for totalt antall symptomer og for ulike grupper av luftveissymptomer. 43,3\% anga færre symptomer totalt og 20,9\% flere symptomer, mens 35,8\% rapporterte om samme antall symptomer.

\section{Diskusjon}

Det er en begrensning ved vår studie at symptomendringen ble målt over et kort tidsintervall, og det standardiserte spørreskjemaet som vi brukte var ikke ideelt til å måle endringer over kort tid. Dette vil imidlertid medvirke til å redusere sanne forandringer i symptomer over tid, og slik underestimere kontrastene mellom målingene.

Denne studien, med høy responsrate, rapporterer resultatet fra en situasjon som ligger nær opptil det man kan kalle et naturlig eksperiment der hver person fungerer som sin egen kontroll. Dette gir en stor grad av kontroll over eksponeringssituasjonen. Resultatene i studien er basert på et lite antall barog restaurantarbeidere, men det er en styrke at undersøkelsene ble gjort på de samme personene, på de samme arbeidsplassene, til samme tidspunkt på døgnet, både før og etter røykeforbudet.

Selvrapporterte data har som kjent svakheter, men selvrapporterte luftveissymptomer kan være en bedre indikator på helse enn vanligvis antatt. Frostad og medarbeidere viste at antall symptomer fra luftveiene signifikant predikerte dødelighet etter en oppfølging på 30 år (12).

En metodologisk svakhet var at undersøkelsene ble gjort på to ulike årstider - sesongvariasjonen kan influere på symptomangivelsene og på resultatene for måling av lungefunksjo- nen. Etterundersøkelsen ble foretatt da temperaturen lå gjennomsnittlig $6^{\circ} \mathrm{C}$ lavere enn ved første runde. Man kan tenke seg at kaldt vær gir bronkokonstriksjon blant personer med reaktive luftveier (13). Vi var imidlertid nødt til å etterundersøke personene forholdsvis kort tid etter første runde pga. høy gjennomtrekk i bransjen. Dette er demonstrert ved at flere hadde sluttet i arbeidsforholdet allerede få måneder etter første oppfølging. I tilsvarende undersøkelse blant bartendere fra Skottland, der man også fant færre symptomer etter at røykeforbud i barer var innført, var man bare i stand til å etterundersøke ca. 50\% henholdsvis ett og tre år etter røykeforbudet (14).

Når det gjelder symptomrapportering og sesongvariasjon, viser andre studier at slike sesongvariasjoner først og fremst er til stede blant svært unge eller svært gamle personer $(15,16)$ og altså ikke så aktuelt for den populasjonen vi undersøkte.

Man kan også tenke seg at øvre luftveisinfeksjoner er mer prevalente i vinterhalvåret, men data fra De britiske øyene tyder ikke på stor forskjell i forekomsten av akutt bronkitt i januar og mai måned (15).

Den høye andelen røykere blant respondentene kan være grunnen til at totalgruppen rapporterte mange symptomer før røykeforbudet. Funn fra lungefunksjonsmålingene kan indikere en effekt av passiv røyking på de små luftveiene før lovendringen (10), noe som kan forklare at en høy andel ansatte anga færre symptomer etter forbudet. Nikotinnivået i barene og restaurantene vi under-

Tabell 1 Symptomprevalens, etter British Medical Research Council Questionnaire (11), i studie av luftveissymptomer blant ansatte før innføring av røykeforbud på serveringssteder. Sp.m. refererer til spørsmålsnummer i spørreskjemaet

\begin{tabular}{|c|c|c|c|c|c|c|c|c|c|c|}
\hline \multirow[b]{2}{*}{ Sp.m. } & \multirow[b]{2}{*}{ Spørsmål } & \multicolumn{3}{|c|}{ Totalgruppe $(\mathrm{N}=86)$} & \multicolumn{3}{|c|}{ Røykere (n = 53) } & \multicolumn{3}{|c|}{ Ikke-røykere (n = 33) } \\
\hline & & Antall & $(\%)$ & $95 \% \mathrm{KI}$ & Antall & $(\%)$ & $95 \% \mathrm{KI}$ & Antall & $(\%)$ & $95 \% \mathrm{KI}$ \\
\hline 1 & Hoster du vanligvis om morgenen? & 23 & $(26,7)$ & $18,0-37,6$ & 16 & $(30,2)$ & $18,7-44,5$ & 7 & $(21,2)$ & $9,6-39,4$ \\
\hline 2 & Hoster du vanligvis i løpet av resten av dagen? & 22 & $(25,6)$ & $17,1-36,3$ & 16 & $(30,2)$ & $18,7-44,6$ & 6 & $(18,2)$ & $7,6-36,1$ \\
\hline 3 & Har du vanligvis slim når du hoster? & 15 & $(17,4)$ & $10,4-27,5$ & 9 & $(17,0)$ & $8,5-30,3$ & 6 & $(18,2)$ & $7,6-36,2$ \\
\hline 4 & $\begin{array}{l}\text { Hoster du vanligvis daglig i } 3 \text { måneder eller mer } \\
\text { i løpet av et år? }\end{array}$ & 13 & $(15,1)$ & $8,6-24,8$ & 8 & $(15,1)$ & $7,2-28,1$ & 5 & $(15,2)$ & $5,7-32,7$ \\
\hline 5 & $\begin{array}{l}\text { I løpet av de siste } 3 \text { årene, i forbindelse med forkjølelse, } \\
\text { har du hatt hoste og/eller oppspytt i mer enn } 3 \text { uker? }\end{array}$ & 30 & $(34,9)$ & $25,1-46,0$ & 18 & $(34,0)$ & $21,9-48,4$ & 12 & {$[36,4]$} & $21,0-54,9$ \\
\hline 6 & $\begin{array}{l}\text { Blir du mer tungpusten enn andre på din alder } \\
\text { når du går opp en bakke? }\end{array}$ & 20 & $(23,3)$ & $15,1-33,8$ & 17 & $(32,1)$ & $20,3-46,4$ & 3 & $(9,1)$ & $2,4-25,5$ \\
\hline 7 & $\begin{array}{l}\text { Blir du tungpusten når du går opp to trapper } \\
\text { i normal hastighet? }\end{array}$ & 16 & $(18,6)$ & $11,3-28,8$ & 11 & $(20,8)$ & $11,3-34,5$ & 5 & $(15,2)$ & $5,7-32,7$ \\
\hline 8 & $\begin{array}{l}\text { Blir du tungpusten når du går i normal hastighet } \\
\text { på flatt grunnlag? }\end{array}$ & 1 & $(1,2)$ & $0,6-7,2$ & 1 & $(1,9)$ & $0,0-11,4$ & 0 & $(0,0)$ & $0,0-13,0$ \\
\hline 9 & Blir du tungpusten når du sitter stille? & 0 & $(0,0)$ & $0,0-5,3$ & 0 & $(0,0)$ & $0,0-8,4$ & 0 & $(0,0)$ & $0,0-13,1$ \\
\hline 10 & Får du noensinne anfall med tungpust? & 8 & $(9,3)$ & $4,4-18,0$ & 7 & $(13,2)$ & $5,9-26,0$ & 1 & $(3,0)$ & $0,2-17,5$ \\
\hline 11 & Har du noensinne hatt piping I brystet? & 39 & $(45,3)$ & $34,7-56,4$ & 29 & $(54,7)$ & $40,6-68,2$ & 10 & $(30,3)$ & $16,2-48,9$ \\
\hline 12 & $\begin{array}{l}\text { Har du hatt luftveisinfeksjon (forkjølelse, oppspytt, } \\
\text { tungpust, piping) i løpet av den siste uken? }\end{array}$ & 28 & $(32,6)$ & $23,1-43,6$ & 19 & $(35,8)$ & $23,5-50,3$ & 9 & $(27,3)$ & $13,9-45,8$ \\
\hline 13 & $\begin{array}{l}\text { Har du hatt øvre luftveisinfeksjon (forkjølelse, oppspytt, } \\
\text { tungpust, piping) relatert til arbeidet ditt? }\end{array}$ & 20 & $(23,3)$ & $15,1-33,8$ & 13 & $(24,5)$ & $14,2-38,6$ & 7 & $(21,2)$ & $9,6-39,4$ \\
\hline 14 & $\begin{array}{l}\text { Hvis du svarte ja på det siste spørsmålet: Ble det en } \\
\text { bedring av symptomene når du var vekk fra arbeidet } \\
\text { (helgene, ferie ol.)? }\end{array}$ & 10 & $(11,6)$ & $29,9-70,1$ & 6 & $(11,3)$ & $4,7-23,7$ & 4 & $(12,1)$ & $4,0-29,1$ \\
\hline
\end{tabular}


Tabell 2 Andel av ansatte ved serveringssteder som rapporterte om færre, flere eller samme antall luftveissymptomer etter innføring av røykeforbud på serveringssteder. Sp.m. refererer til spørsmålsnummer i spørreskjemaet

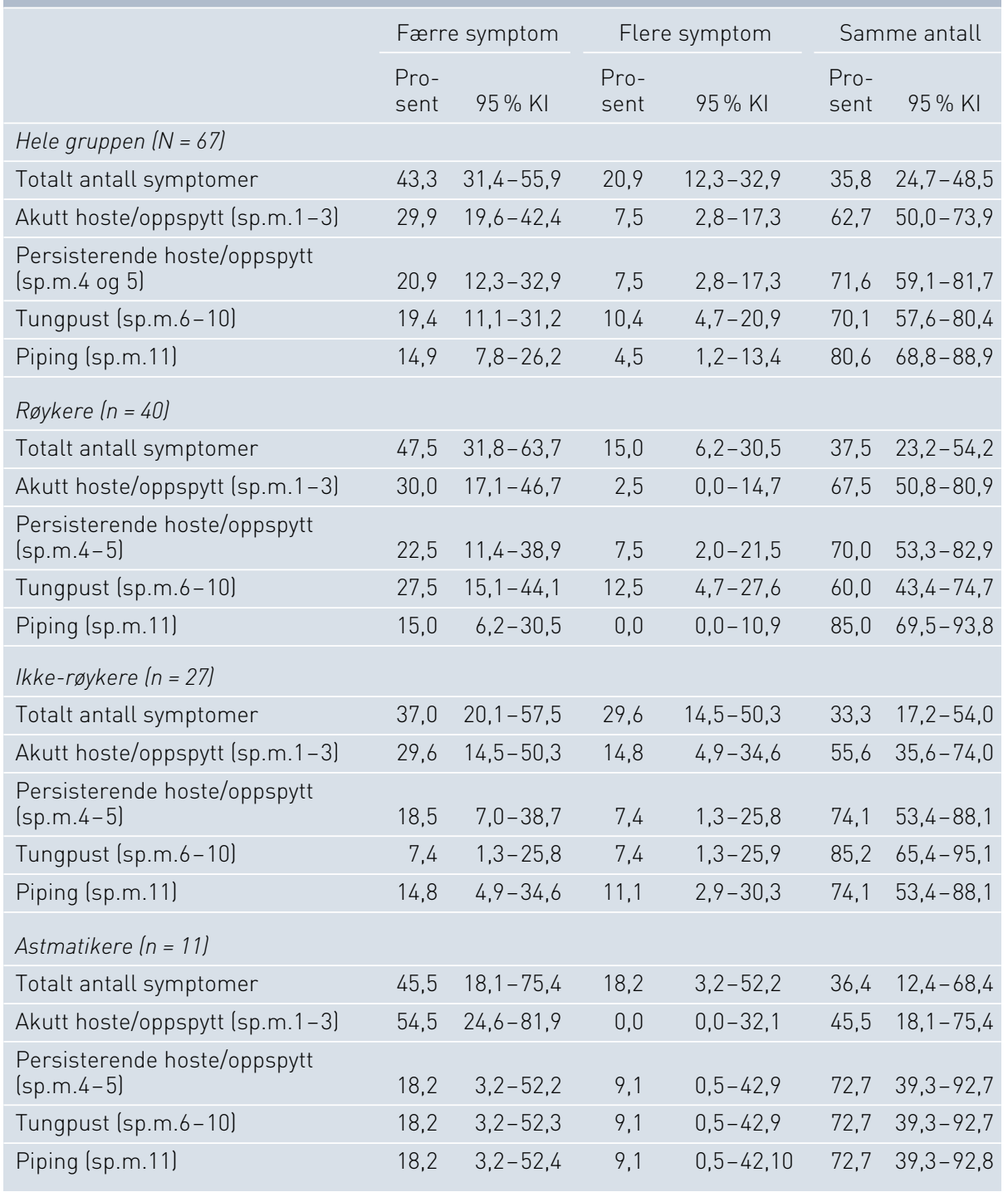

søkte (9) er i samsvar med det man har målt i liknende studier (17), og ligger i området 2,3-65,5 $\mu \mathrm{g} / \mathrm{m}^{3}$ (9). Etter lovendringen var støvnivået på størrelse med det man ser i kontorlandskap (18).

Vi fant at røykerne i større grad enn ikkerøykerne anga færre symptomer etter røykeforbudet. Etter røykeforbudet ble det målt lavere nivåer av kotinin i urin blant røykerne enn før forbudet (9), noe som kan tyde på at de røykte mindre etter lovendringen. Dette er i tråd med en befolkningsundersøkelse i Norge som viser at røykere har redusert sitt forbruk med $7-9 \%$ og at $10 \%$ av dagligrøykerne hadde sluttet å røyke etter røykeforbudet (19).

\section{Konklusjon}

Denne delstudien viser at innføring av røykeforbud på serveringssteder kan være gunstig for helsen til de ansatte ved at en høy andel rapporterte om færre luftveissymptomer etter forbudet. Imidlertid var det overraskende mange, ca. $20 \%$ av totalgruppen, som anga flere symptomer.

\section{Marit Skogstad (f. 1955)}

er dr.med. og spesialist i arbeidsmedisin. Hun er forskningssjef ved Statens arbeidsmiljøinstitutt i Oslo, har i mange år jobbet med lungeproblemstillinger i fagområdet arbeidsmedisin.

Ingen oppgitte interessekonflikter.

\section{Kristina Kjærheim (f. 1953)}

er dr.med., overlege og nestleder ved Forskningsavdelingen ved Kreftregisteret. Ingen oppgitte interessekonflikter.

\section{Geir Fladseth (f. 1970)}

arbeider som yrkeshygieniker i konsulentselskapet Occupational Hygienene Solutions AS (Ohs), som er en del av Proactima-konsernet. Er for tiden innleid i Shell som yrkeshygieniker i drift for Ormen Lange og Draugen, samt yrkeshygieniker for Umoe Restaurant Group. Jobbet i perioden 1997-2007 ved Statens arbeidsmiljøinstiutt, gikk i november 2007 over til Ohs, hvor han jobber fremdeles. Ingen oppgitte interessekonflikter.

\section{Pål Molander (f. 1970)}

er dr.scient. i analytisk kjemi. Han er direktør ved Statens arbeidsmiljøinstitutt og professor II ved Kjemisk institutt, Universitetet i Oslo, har tidligere vært forsker og forskningsdirektør ved Statens arbeidsmiljøinstitutt

Ingen oppgitte interessekonflikter.

\section{Litteratur}

1. Hackshaw AK, Law MR, Wald NJ. The accumulated evidence on lung cancer and environmental tobacco smoke. BMJ 1997. 315: $980-8$

2. Boffetta P. Involuntary smoking and lung cancer. Scand J Work Environ Health 2002; 28 (suppl 2): $30-40$.

3. Law MR, Morris JK, Wald NJ. Environmental tobacco smoke exposure and ischaemic heart disease: an evaluation of the evidence. BMJ 1997 315: $973-80$

4. Jousilahti P, Patja K, Salomaa V. Environmental tobacco smoke and the risk of cardiovascular disease. Scand J Work Environ Health 2002; 28 (suppl 2): 41-51.

5. Coultas DB. Health effects of passive smoking. 8. Passive smoking and risk of adult asthma and COPD: an update. Thorax 1998; 53: 381-7.

6. Jaakkola MS, Jaakkola JJK. Effects of environmental tobacco smoke on the respiratory health of adults. Scand J Work Environ Health 2002; 28 (suppl 2): 52-70.

7. Lefcoe NM, Ashley MJ, Pederson LL et al. The health risks of passive smoking. The growing case for control measures in enclosed environments. Chest 1983; 84: 90-5.

8. Siegel M. Involuntary smoking in the restaurant workplace. A review of employee exposure and health effects. JAMA 1993; 270: 490-3.

9. Ellingsen DG. Fladseth $\mathrm{G}$, Daae $\mathrm{HL}$ et al. Airborne exposure and biological monitoring of bar and restaurant workers before and after the introduction of a smoking ban. J Environ Monit 2006 8: 362-8.

10. Skogstad M, Kjaerheim K, Fladseth $G$ et al. Cross shift changes in lung function among bar and restaurant workers before and after implementation of a smoking ban. Occup Environ Med 2006 63: $482-7$

11. Standardized questionnaire on respiratory symptoms. BMJ 1960: 2: 1665

12. Frostad A, Søyseth V, Andersen A et al. Respiratory symptoms as predictors of all-cause mortality in an urban community: a 30-year follow-up. J Intern Med 2006; 259: 520-9.

13. Mckerrow CB, Rossiter CE. An annual cycle in the ventilatory capacity of men with pneumoconiosis and of normal subjects. Thorax 1968; 23: 340-9.

14. Ayres JG, Semple S, MacCalman L et al. Bar workers' health and environmental tobacco smoke exposure (BHETSE): symptomatic improvement in bar staff following smoke-free legislation in Scotland. Occup Environ Med 2009; 66: 339-46.

15. Ayres JG. Seasonal pattern of acute bronchitis in general practice in the United Kingdom 1976-83. Thorax 1986; 41: 106-10.

16. Osborne ML, Vollmer WM, Buist AS. Periodicity of asthma, emphysema, and chronic bronchitis in a northwest health maintenance organization. Chest 1996; 110: 1458-62.

17. Trout D, Decker J, Mueller $C$ et al. Exposure of casino employees to environmental tobacco smoke. J Occup Environ Med 1998; 40: 270-6.

18. Skulberg KR, Skyberg K, Kruse K et al. The effect of cleaning on dust and the health of office workers: an intervention study. Epidemiology 2004; 15: $71-8$

19. Hetland J, Aaro LE. Røykevaner, holdninger til røykfrie serveringssteder og opplevelse av håndhevingsproblemer i serveringsbransjen - en prospektiv panelundersøkelse. Oslo: SIRUS, 2005.

Mottatt 3.3. 2009, første revisjon innsendt 28.8. 2009, godkjent 7.7. 2011. Medisinsk redaktør Trine B. Haugen. 